\title{
Prosodic Preferences: \\ From Old English to Early Modern English*
}

\author{
Paula Fikkert, Elan B. Dresher \& Aditi Lahiri \\ draft February 18, 2005
}

\section{$1 \quad$ Introduction}

This chapter discusses the prosodic organisation of the phonological and morphological system of Old English, and investigates how this system changed up to early Modern English. By prosody we mean primarily aspects of the grammar related to the weight of root syllables, syllable structure, and stress. ${ }^{1}$ Although the changes we will discuss are primarily phonological, a proper understanding of prosodic change in the history of English requires that we take into account morphological class membership, particularly as stem extensions and endings played a significant role in many of the phonological rules that ultimately affected the prosodic organisation of the language. In addition, the quantity of root syllables played a crucial role in constraining prosodic changes throughout the history of English.

We assume that the major developments under review here came about in the process of transmission of the language from one generation to the next, that is, in the course of language acquisition. Prominent in our account will be a characteristic of grammars called pertinacity (Lahiri 2002). A rule or pattern in the native speaker's grammar may persist over time, though its outward realization may change. An example is the persistence of a particular metrical pattern in English, the Germanic foot. We will show that this foot pattern came to apply to new forms, such as Romance loans in Middle English, and applied in a new way to certain older forms. This type of prosodic change occurs when learners extend a grammatical pattern to new forms. The grammatical pattern is transmitted to the next generation, but sometimes with different outward manifestations due to other changes in the grammar.

Another type of pertinacity concerns the persistence of the native output forms despite changes in the grammar. We will show that despite major changes in the 
metrical system in early Modern English, native English words retained the original position of main stress, while the grammar restructured all around them. Since learners acquire their grammar guided by the output forms they are exposed to, we do not expect the forms that make up the 'core' or 'primary' data to change in the course of acquisition. However, when such core forms fail to provide unambiguous evidence as to the nature of the underlying grammar, the way is opened for new forms to cause a change in the grammar.

Both types of pertinacity imply conservatism, either in the grammar or in the surface forms. But the acquisition process can also result in radical changes where neither grammar nor outputs remain the same. Such upheavals occur when, due to the interaction of various phonological and morphological processes, the underlying forms become unrecoverable (Kaye 1974), or the grammatical principles that give rise to the surface forms become opaque (Kiparsky 1982, 2000). When the opacity is such that language learners could not reconstruct the old system, they may instead adopt strategies, such as paradigmatic levelling, that lead to dramatic changes in both grammar and output.

In this chapter we first discuss the prosodic system of West Germanic, which remained largely unchanged in Old English. Subsequently, we will show how a number of phonological rules directly or indirectly influenced the West Germanic nominal paradigms which led to the Old English situation. Many of these rules affected light and heavy root syllables differently and consequently affected morphological paradigms as well. In this chapter we will restrict ourselves to the nominal system, but it is important to note that the effects also hold for the verbal system. From Old English to Middle English the prosodic system underwent processes such as High Vowel Deletion (HVD), Trisyllabic Shortening (TSS) and Open Syllable Lengthening (OSL). While the last two processes served to optimize metrical structures in ways we will discuss, they also gave rise to new types of vowel length alternations in morphological paradigms. Furthermore, subsequent processes such as final vowel deletion often obscured the contexts of these vowels length alternations, making the phonology opaque. This opacity lead to paradigm levelling, simplifying the morphological system, but altering the prosodic system.

Despite the fact that many words changed their prosodic word structure, we present evidence from Romance loan words into Middle English showing that the prosodic system in Middle English was still essentially the same as that of Old 
English. In other words, no new stress rules were taken over from the donor language. However, loans may ultimately have an effect on the stress system, which we argue is the case when long Latin words were borrowed into early Modern English. When the native stress rules are indecisive, loan words can trigger a change. This, we argue, led to the modern English Latinate stress system.

\section{The word prosodic system of West Germanic}

Stress in West Germanic and in Old English invariably falls on the first syllable of the word, unless the word is prefixed, in which case the prefix is stressed in nouns, but not in verbs. The stress system of Old English is much debated (cf. Dresher \& Lahiri 1991, 2004; Kiparsky 1998, Minkova, this volume). Here, we will follow Dresher \& Lahiri (1991), who argue that the metrical foot is a resolved and expanded moraic trochee $([\mu \mu(\mu)] \mu)$, where the head, indicated by square brackets, must dominate at least two moras. When the stressed syllable is light, that is, when the two moras of the head could not have come from one syllable, it is 'resolved'. In that case the head is formed by the first two syllables regardless of the weight of the second syllable. In parametric terms, the Germanic metrical structure is as in (1) with sample parsings from Old English.

(1) The Germanic Foot (Dresher \& Lahiri 1991)

Foot type: resolved (expanded) moraic trochee $([\mu \mu(\mu)] \mu)$

Direction of parsing: left to right

Main stress: Left

Sample parsings

$\begin{array}{ccc}(\mathrm{x} \quad .) & (\mathrm{x} \quad .) & (\mathrm{x} \quad .) \\ ([\mu \mu] \mu) & ([\mu \mu] \mu) & ([\mu \mu \mu] \mu) \\ \mathrm{H} \quad \mathrm{L} & \mathrm{L} \mathrm{L} \mathrm{L} & \mathrm{L} \mathrm{H} \mathrm{L} \\ \text { wor da } & \text { we ru da } & \text { cy nin ga }\end{array}$


Given this formulation of Old English metrical structure, we would expect all heavy syllables, except those following an initial light syllable, to be stressed. This might have been the case in earlier times, but in Old English no final syllable, whether heavy or light, bears secondary stress (Campbell 1959: $§ \S 87-92)$. A non-initial foot can bear secondary stress only if it is branching. Thus, we find alternations such as óðer $\sim \overline{o ́ ð e ̀ r n e ~ ' o t h e r, ~ N O M . ~ S I N G . ~ ~ A C C . ~ S I N G . ' ~ a n d ~ c e ́ ð e l i n g ~ ~ ~ c e ́ ð e l i n g e s ~ ' p r i n c e, ~}$ NOM. SING. $\sim$ GEN. SING.' Their metrical structures are shown in (2), where an underlined $\mathrm{x}$ indicates a syllable that lacks secondary stress, despite being the head of a foot:

(2) Lack of secondary stress in final syllables (Dresher \& Lahiri 1991)

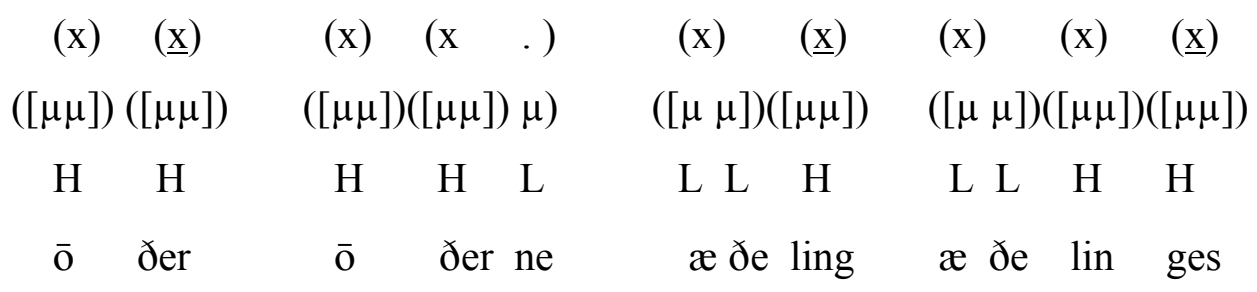

This systematic failure of final syllables to be stressed suggests a rule such as Final Destressing (FD):

Final Destressing (FD)

Defoot a final weak non-branching foot.

In Old English all unstressed long vowels, including those in final syllables, were shortened, which made a subtle reanalysis of the prosodic system possible. In the absence of unstressed long vowels, the only word-final syllables that appeared to be heavy were those ending in a consonant. The fact that such syllables did not receive secondary stress could then be accounted for in terms of Final Consonant Extrametricality (CEM):

(4) Final Consonant Extrametricality (CEM)

Word-final consonants are extrametrical. 
Dresher and Lahiri provide several types of evidence supporting the Germanic foot, including main and secondary stress, High Vowel Deletion (HVD) in Old English, and Sievers' Law in Gothic. Additional evidence for the Germanic foot and the reanalysis of Final Destressing (3) as Consonant Extrametricality (4) comes from OSL (Lahiri \& Dresher 1999), TSS (Lahiri \& Fikkert 1999) and the dental preterit (Lahiri 1999, 2004). We will discuss some of the evidence below.

A key concept in the discussion of the prosodic systems of Germanic and their change is weight or quantity. It played a crucial role in the changes in the old inherited morphological paradigms from West Germanic to Old English. Syllables in Old English can be characterised as either light, heavy, or superheavy. Light syllables contain a non-branching rhyme (V). Heavy syllables have rhymes with either a branching nucleus (VV) or a branching rhyme (VC). Superheavy syllables contain VVC or VCC rhymes. All these syllable types occur in Old English, but an important further restriction is that root $^{2}$ syllables cannot consist of a single light syllable. The minimal requirement for a monosyllabic root is a heavy syllable: $\mathrm{VV}$ or $\mathrm{VC}_{1}{ }^{3}$ Roots consisting of a heavy CVC syllable are called light roots: A CVC root plus a vowelinitial ending would syllabify as CV.CV, making the initial (root) syllable light. All other root syllables are heavy. Most roots in Old English are monosyllabic - which explains the term root syllable - although there are longer roots, too.

The table in (5) presents the nominative singular and plural forms as they are attested in Old English. The first column gives the traditional name of the nominal class (after their stem extensions), and the genders it came in: masculine (m.), feminine (f.), or neuter (n.). The main Proto-Germanic stem extensions were $a$-, jafor masculine and neuter nouns, $\bar{o}-, j \bar{o}$ - for feminines, and $i$ - and $u$ - in all genders, although $u$-neuters went over to the $a$-nouns at an early stage.

(5) Survey of strong nominal classes - light and heavy roots ${ }^{4}$

\begin{tabular}{|l|l|l|l|}
\hline Class & Sing. & Plur. & Gloss \\
\hline \multirow{2}{*}{$a-\quad(\mathrm{m})}$. & $\mathrm{d} g$ & dagas & 'day' \\
\cline { 2 - 4 } & stān & stānas & 'stone' \\
\hline \multirow{2}{*}{$j a-(\mathrm{m})}$. & hyll & hyllas & 'hill' \\
\cline { 2 - 4 } & ende & endas & 'end' \\
\hline$a-\quad(\mathrm{n})$. & hol & holu & 'hole' \\
\hline
\end{tabular}




\begin{tabular}{|c|c|c|c|}
\hline & word & word & 'word' \\
\hline \multirow{2}{*}{$j a-(\mathrm{n})}$. & bedd & bedd & 'bed' \\
\hline & gewǣde $^{5}$ & gewǣdu & 'clothing' \\
\hline \multirow{2}{*}{$\bar{o}-\quad(\mathrm{f})}$. & talu & tale, -a & 'tale' \\
\hline & $\bar{a} \mathbf{r}$ & āre, -a & 'honour' \\
\hline \multirow{2}{*}{$j \bar{o}-$ (f.) } & synn & synne, -a & 'offence' \\
\hline & sprēc & sprēece, -a & 'speech' \\
\hline \multirow{2}{*}{$i-\quad(\mathrm{m})}$. & byre & byras & 'son' \\
\hline & gylt & gyltas & 'guilt' \\
\hline \multirow{2}{*}{$i-\quad(\mathrm{n})}$. & spere & speru & 'spear' \\
\hline & gecynd & gecyndu & 'nature' \\
\hline$i-\quad$ (f.) & wyrd & wyrde, a & 'fate' \\
\hline \multirow{2}{*}{$u-\quad$ (m., f.) } & sunu & suna & 'son' \\
\hline & feld & felda & 'field' \\
\hline
\end{tabular}

Old English inherited from its Germanic and ultimately Indo-European ancestors a system of noun classes that took the form Root + Extension + Suffix, which is reflected in (6). The table in (6) gives a sample of some of the nominal classes of preOld English with examples of their nominative singular-plural suffixes. Reconstructed underlying stems are given. ${ }^{6}$

(6) Survey of strong nominal classes - light and heavy roots

\begin{tabular}{|c|c|c|c|c|c|}
\hline Class & $\begin{array}{l}\text { Sing. } \\
\text { suffix }\end{array}$ & $\begin{array}{l}\text { Plur. } \\
\text { suffix }\end{array}$ & Weight & $\begin{array}{l}\text { Root }+ \\
\text { Extension }\end{array}$ & Gloss \\
\hline \multirow{2}{*}{$a-\quad(\mathrm{m})}$. & \multirow{4}{*}{ /+Ø/ } & \multirow{4}{*}{$/+\mathrm{as} /$} & light & /dæg/ & 'day' \\
\hline & & & heavy & /stān/ & 'stone' \\
\hline \multirow{2}{*}{$j a-(\mathrm{m})}$. & & & light & $/ \mathrm{hul}+\mathrm{j} /$ & 'hill' \\
\hline & & & heavy & /and $+\mathrm{j} /$ & 'end' \\
\hline \multirow{2}{*}{$a-\quad$ (n.) } & \multirow[t]{3}{*}{$1+\varnothing /$} & \multirow[t]{3}{*}{$/+\mathrm{u} /$} & light & /hol/ & 'hole' \\
\hline & & & heavy & /word/ & 'word' \\
\hline$j a-(\mathrm{n})$. & & & light & $/ \mathrm{bad}+\mathrm{j} /$ & 'bed' \\
\hline
\end{tabular}




\begin{tabular}{|c|c|c|c|c|c|}
\hline & & & heavy & /gewād+j/ & 'clothing' \\
\hline \multirow{2}{*}{$\bar{o}-\quad$ (f.) } & \multirow{4}{*}{$/+\varnothing /$} & \multirow{4}{*}{$/+\mathrm{e} \sim \mathrm{a} /$} & light & $/ \mathrm{tal}+\mathrm{u} /$ & 'tale' \\
\hline & & & heavy & $/ \bar{a} \mathrm{r}+\mathrm{u} /$ & 'honour' \\
\hline \multirow{2}{*}{$j \bar{o}-(\mathrm{f})}$. & & & light & $/$ sun+ju/ & 'offence' \\
\hline & & & heavy & /sprāc+ju/ & 'speech' \\
\hline \multirow{2}{*}{$i-\quad(\mathrm{m})}$. & \multirow{2}{*}{$/+\varnothing /$} & \multirow{2}{*}{ /+e $\sim$ as/ } & light & $/$ bur $+\mathrm{i} /$ & 'son' \\
\hline & & & heavy & $/$ gult $+\mathrm{i} /$ & 'guilt' \\
\hline \multirow{2}{*}{$i-\quad(\mathrm{n})}$. & \multirow{2}{*}{$/+\varnothing /$} & \multirow{2}{*}{$/+\mathrm{u} /$} & light & /sper $+\mathrm{i} /$ & 'spear' \\
\hline & & & heavy & /gecund $+\mathrm{i} /$ & 'nature' \\
\hline \multirow{2}{*}{$i-\quad($ f. $)$} & \multirow{2}{*}{$/+\varnothing /$} & \multirow{2}{*}{$/+\mathrm{e} \sim \mathrm{a} /$} & light & -----' & \\
\hline & & & heavy & /wurd $+\mathrm{i} /$ & 'fate' \\
\hline \multirow{2}{*}{$u-\quad$ (m., f.) } & \multirow{2}{*}{$/+\varnothing /$} & \multirow{2}{*}{$/+\mathrm{a} /$} & light & $/ \operatorname{sun}+\mathrm{u} /$ & 'son' \\
\hline & & & heavy & $/$ feld $+\mathrm{u} /$ & 'field' \\
\hline
\end{tabular}

The largest classes in Old English came to be the $a$ - and the $\bar{o}$-nouns. In early times the $a$-extensions were reanalysed as being part of the suffixal inflection; thus, stems in these classes appear in the chart without any extension. All other classes show a stem extension in (6). A significant subclass of these nouns, called $j a$ - and $j \bar{o}$ - nouns, had a formative we represent as an extension $-j$. Although the stem extension and nominative suffixes of $\bar{o}$ - and $j \bar{o}$ - nouns are alike, the words in each class are distinguished by genitive and dative case suffixes. The table further gives the singular and plural endings of the nominative and the weight of the root.

The symmetrical West Germanic system represented in (6), with light and heavy roots for each class, would later be disturbed by the effects of several phonological rules, as can be seen in (5). We discuss these rules in the next section. We shall see that the distinction between light and heavy roots plays a central role in many of the main phonological-prosodic processes of Old English. Also of prosodic interest is the distinction between the formatives designated as $j$ - and $i$-; we will see evidence that these must have different representations, but for now we assume that the $j$ - is a floating $i$ (following Kiparsky 1998, 2000, 2002). We will come back to this issue. 


\section{From West Germanic to Old English}

\subsection{Sievers' Law}

The distinction between light and heavy roots had been reinforced by Sievers' Law (Sievers, 1885) in the ancestor of the Germanic languages. In the formulation of Edgerton $(1934,1943)$, the $-j$ extension takes the form $j$ after a light stem and $i j$ (ii) after a heavy stem. Therefore, the $j a$ - and $j \bar{o}$ - nouns, at an early stage, would have appeared as in (7). This alternation did not affect the $-i$ extension, showing it was a distinct element from $-j$.

(7) Sievers' Law - light and heavy roots

\begin{tabular}{|l|l|l|l|}
\hline Class & Weight & Sievers' Law & Gloss \\
\hline \multirow{2}{*}{$j a-(m)}$. & light & hul $+^{\mathrm{i}}$ & 'hill' \\
\cline { 2 - 4 } & heavy & and $+\mathrm{i}^{\mathrm{i}}$ & 'end' \\
\hline \multirow{2}{*}{$j a-(n)}$. & light & bad $+^{\mathrm{i}}$ & 'bed' \\
\cline { 2 - 4 } & heavy & gewād $+\mathrm{i}^{\mathrm{i}}$ & 'clothing' \\
\hline \multirow{2}{*}{$j \bar{o}-(\mathrm{f})}$. & light & sun $+{ }^{\mathrm{i}} \mathrm{u}$ & 'sin' \\
\cline { 2 - 4 } & heavy & sprāc $+{ }^{\mathrm{i}} \mathrm{u}$ & 'rest' \\
\hline
\end{tabular}

We will assume that Sievers' Law optimized the prosodic structure by avoiding $\mathrm{Cj}$ clusters (Dresher \& Lahiri 1991, Riad 1992, Kiparsky 1999). In $s p r a \bar{c}+{ }^{i} u$ Sievers’ law could not improve the prosodic structure, but rather would have created a sequence of too many high vowels in a row; hence, no extra vowel was added here.

\section{$3.2 \quad$ i-Umlaut (i-Mutation)}

A high front vowel or glide ( $i$ or $j$ in the table in (6)) causes fronting (and in some cases raising) of a preceding stressed vowel. This rule of Umlaut is evidently an early rule, as it affects all the West Germanic dialects. In Old English it applies before High Vowel Deletion or apocope, as it affects the singular of heavy $i$-stems, as in gest $i$ 'guest', unlike in Old High German, where gast is not umlauted. In terms of 
morphological classes, umlaut systematically affected $j a-, j \bar{o}-$, and $i$ - nouns, as shown in (8):

Effects of $i$-Umlaut on stressed vowels

\begin{tabular}{|c|c|c|c|}
\hline Class & Root+Extension & $i$-Umlaut & Gloss \\
\hline \multirow{3}{*}{ ja- (m.) } & $/$ hul $^{\mathrm{i}} /$ & hyl $+^{i}$ & 'hill' \\
\hline & $/$ hart $^{\mathrm{i}} /$ & hert ${ }^{1}$ & 'army' \\
\hline & /and $+\mathrm{i}^{1}$ & end $+\mathrm{i}^{\mathrm{i}}$ & 'end' \\
\hline \multirow{3}{*}{$j a-(\mathrm{n})}$. & $/$ bad $^{\mathrm{i}} /$ & bed $+^{i}$ & 'bed' \\
\hline & $/$ stucc $+\mathrm{i}^{\mathrm{i}} /$ & stycc $+\mathrm{i}^{1-}$ & 'stick' \\
\hline & / gewād $+\mathrm{i}^{\mathrm{i}} /$ & gewǣ $\bar{d}+\mathrm{i}^{\mathrm{i}}$ & 'clothing' \\
\hline \multirow{2}{*}{$j \bar{o}-(\mathrm{f})}$. & $/ \operatorname{sun}+\mathrm{u} /$ & $\operatorname{syn}+\mathrm{u}$ & 'offence' \\
\hline & sprāc $+{ }^{i} u$ & sprēec $+{ }^{i} u$ & 'rest' \\
\hline \multirow{2}{*}{$i-\quad(\mathrm{m})}$. & /bur $+\mathrm{i} /$ & byr $+\mathrm{i}$ & 'friend' \\
\hline & /gult $+\mathrm{i} /$ & gylt $+\mathrm{i}$ & 'guilt' \\
\hline \multirow{2}{*}{$i-\quad($ n. $)$} & /sper $+\mathrm{i} /$ & sper $+\mathrm{i}$ & 'spear’ \\
\hline & /gecund $+\mathrm{i} /$ & gecynd $+\mathrm{i}$ & 'nature' \\
\hline$i-\quad$ (f.) & /wurd $+\mathrm{i} /$ & wyrd $+\mathrm{i}$ & 'fate' \\
\hline
\end{tabular}

Because the umlauting element was present throughout the nominal paradigm no alternations are created within these classes. However, alternations were created in other classes, such as in the consonantal stems, where high front vowels or glides appeared in certain suffixes but not others, giving rise to alternations in singularplural pairs like $f \bar{o} t-f \bar{e} t$, and in derivationally related words belonging to different lexical classes, such as lang - lengð(u) ('long' - 'length').

Therefore, $i$-Umlaut remained as a synchronic rule in Old English for some time, at least in paradigms where it created alternations. Where there were no alternations the matter is less clear-cut. As long as vowels newly-created by umlaut, such as $y$ and $c e$, were recognised as positional allophones of $u$ and $o$, forms such as gylt- would be interpreted as deriving from /gult-/. As long as the umlauting element remained detectable, it should not have been difficult for the learner to discern that umlauted vowels were in complementary distribution with corresponding non- 
umlauted vowels. However, the intervention of further changes would considerably complicate the situation.

\subsection{West Germanic Gemination (WGG)}

Another early process that applied throughout West Germanic is West Germanic Gemination (WGG). Gemination applied to all root-final consonants other than $r$ when $j$ followed. Since gemination adds a mora to the first syllable, forms could undergo gemination only if the prosodic structure of the root syllable was able to include another mora. If the root syllable already contained two moras, (i.e., was heavy, as in end, stucc, or spréc) gemination could not take place. We refer to this as the bimoraicity constraint on root syllables $(* \mu \mu \mu)$. If the root syllable contained a single mora, as in the case of hyl, bed, or syn, the root underwent gemination.

Effects of Gemination on light roots

\begin{tabular}{|c|c|c|c|c|}
\hline Class & Weight & Umlaut & Gemination & Gloss \\
\hline \multirow{2}{*}{$j a-(\mathrm{m})}$. & \multirow{2}{*}{ light } & hyl $+^{i}$ & hyll & 'hill' \\
\hline & & her+ ${ }^{1}$ & her ${ }^{1}$ & 'army' \\
\hline ja- (n.) & light & bed $+^{i}$ & bedd & 'bed' \\
\hline$j \bar{o}-$ (f.) & light & $\operatorname{syn}++^{i} u$ & synnu & 'offence' \\
\hline
\end{tabular}

The effect of WGG is to turn light roots into heavy ones. This change significantly alters the original symmetry of the morphological classes.

Note that the geminating element $j$ in the representations in (9) seems to disappear after gemination, as the surface forms in Old English are respectively, hyll, here, bedd, and synn. There is evidence that in West Germanic, $j$ did not delete in the process of WGG; hence Old High German kunni from /cun $+\mathrm{j} /$. In Old English, too, there are traces left of the $j$, particularly in the heavy ja- and $j \bar{o}$-stems, but not after gemination, as we shall discuss in the next section.

Significantly, the $i$-nouns do not undergo West Germanic gemination. This is a principled motivation for the claim that the element we have been designating as $j$ differs from the extension we have been writing as $i$ : otherwise, it would be hard to explain why $/ \mathrm{hyl}+\mathrm{j} /$ geminates, whereas $/ \mathrm{byr}+\mathrm{i} /$ does not. Under the assumption that the distinction is, as the notation suggests, one between an underlying glide and an 
underlying vowel, there would be an underlying moraic contrast between $j$ and $i$. Such a contrast is unusual, because it is usually assumed that moraicity falls out from syllabification. Whether a segment surfaces as a vowel or glide in Old English is to a large extent predictable. For example, the $j$ extension surfaces as a glide in herjas 'armies NOM., ACC. PL.' but as a vowel $e$ (lowered from $i$ ) in the singular here 'army'.

\begin{tabular}{lllll}
\multicolumn{2}{l}{ Syllabification of $j$} & & \\
Underlying & Umlaut & Syllabification & $\mathrm{i}>\mathrm{e}$ & \\
har- $^{\mathrm{i}}$ & her- $^{\mathrm{i}}$ & he.ri & here & 'army' SG. \\
${\text { har- }{ }^{\mathrm{i}} \text {-as }}^{\text {her- }{ }^{\mathrm{i}} \text {-as }}$ & her.jas & --- & 'army' PL.
\end{tabular}

Nevertheless, some distinction must be made to account for the different behaviour of the $-j$ and $-i$ extensions, as Germanic harj 'army' (light ja-noun) and mari 'see' (light $i$-noun) pattern differently. One possibility is to specify that the $i$ is underlyingly moraic, as in (11a), or equivalently, that it is associated to a nuclear position, whereas $j$ is not. Another possibility, suggested by Kiparsky $(2000,2002)$, is that this contrast rests on the difference between an ordinary segment $(i)$ and a floating one $(j)$, as shown in (11b).

(11) j-i stem extensions

a. $\mu$

$\begin{array}{ll}\mathrm{i} & \mathrm{i}(=\mathrm{j}) \\ / \mathrm{hyp}+\mathrm{i} / & / \text { stycc }+\mathrm{j} /\end{array}$

b. $\quad \mathrm{x}$

floating

i

$\mathrm{i}(=\mathrm{j})$

/hyp $+\mathrm{i} /$

$/$ stycc + i/

We will assume the latter possibility. The floating $j$ of the stem extension is syllabified as a glide when other (vowel-initial) suffixes follow, that is, when it is no longer word edge, but only if syllabification is possible. If it cannot be syllabified it disappears. If the $j$ of the stem extension is word-final, it surfaces as a vowel $i$, which is lowered to $e$. 


\section{$3.4 \quad$ High Vowel Deletion (HVD) and hiatus}

High Vowel Deletion (HVD) is a rule that deletes an unstressed high vowel or glide following a heavy syllable. This is only one its contexts, however; HVD also deletes an unstressed high vowel or glide following two light syllables, or a light followed by a heavy syllable. The generalisation is that HVD applies in the weak branch of a foot, leaving unfooted high vowels intact. In (12), the underlined vowels are in the weak branch of a foot and undergo HVD.

(12) High Vowel Deletion in Old English

\begin{tabular}{|c|c|c|}
\hline$\left(\begin{array}{ll}\mathrm{x} & .\end{array}\right)$ & $\left(\begin{array}{ll}\mathrm{x} & .\end{array}\right)$ & $\left(\begin{array}{lll}\mathrm{x} & .\end{array}\right)$ \\
\hline$([\mu \mu] \mu) \mu$ & $([\mu \mu] \quad \mu)$ & $\left(\left[\begin{array}{ll}\mu & \mu \mu\end{array}\right] \mu\right)$ \\
\hline H L L & $\mathrm{H} \quad \mathrm{L}$ & $\mathrm{L} \quad \mathrm{H} \quad \mathrm{L}$ \\
\hline hēa fü de & wor du & $\mathrm{fæ}$ rel du \\
\hline 'head-DAT.SG' & 'word-NOM.PL' & 'journey-NOM.PL.' \\
\hline.$)$ & $(\mathrm{x})$ & $\left(\begin{array}{ll}\mathrm{x} & .\end{array}\right)$ \\
\hline$\left(\left[\begin{array}{ll}\mu & \mu\end{array}\right] \mu\right)$ & $\left(\left[\begin{array}{ll}\mu & \mu\end{array}\right]\right)$ & $([\mu \mu] \mu) \mu$ \\
\hline L L L & $\mathrm{L} \mathrm{L}$ & $\mathrm{H} \quad \mathrm{L} \mathrm{L}$ \\
\hline we ru du & ho lu & ci ce $n u>$ cicenu $(\mathrm{TSS})^{8}$ \\
\hline 'army- NOM.PL' & 'hole- NOM.PL' & 'chicken-NOM.PL.' \\
\hline
\end{tabular}

Lahiri (1982) notes that there are two conditions under which HVD did not take place. First, HVD did not take place if the high vowel was part of a syllable without an onset. For instance, in the light neuter $i$-noun sper- $i+u$, the $u$ is not deleted. Second, if the high vowel was preceded by a glide HVD was also blocked; in that case the glide was deleted, as we will see when discussing the $j a$-nouns. These conditions were probably more general strategies to avoid hiatus of unstressed vowels. High vowels were more prone to deletion than other vowels. In case of two high vowels, usually the first deletes.

HVD creates a further difference between heavy and light roots in classes in which a high vowel or glide occurs as either an extension or as part of the suffix. Let us consider first the effects on members of the $a$-, $\bar{o}$-, $i$-, and $u$ - classes, where $\varnothing$ 
indicates HVD and _ a vowel deleted to avoid hiatus. The bolded high vowels do not undergo HVD.

(13) Effects of HVD and avoidance of hiatus on $a-, \bar{o}-, i-$, and $u$ - nominal classes

\begin{tabular}{|c|c|c|c|c|}
\hline Weight & $\begin{array}{l}\text { Root+stem } \\
\text { extension }\end{array}$ & SING. & PLUR. & Gloss \\
\hline \multicolumn{2}{|l|}{$a-(\mathrm{n})}$. & $+\varnothing$ & $+\mathrm{u}$ & \\
\hline$L$ & /hol-/ & hol & holu & 'hole' \\
\hline$H$ & /word-/ & word & word $\varnothing$ & 'word' \\
\hline \multicolumn{2}{|l|}{$\bar{O}-$ (f.) } & $+\varnothing$ & $+\mathrm{e} / \mathrm{a}$ & \\
\hline$L$ & /tal-u/ & talu & tal_e, $-\mathrm{a}$ & 'tale' \\
\hline$H$ & $/ \bar{a} \mathrm{r}-\mathrm{u} /$ & $\overline{\operatorname{ar}} \varnothing$ & $\overline{\operatorname{ar}} \varnothing \mathrm{e}$ & 'honour' \\
\hline \multicolumn{2}{|l|}{$i_{-} \quad(\mathrm{m})}$. & $+\varnothing$ & $+\operatorname{as}(/ \mathrm{e})$ & \\
\hline$L$ & /byr-i/ & byre & byr_as, -e & 'son’ \\
\hline$H$ & /gylt-i/ & gylt Ø & gylt $\varnothing$ as & 'guilt' \\
\hline \multicolumn{2}{|l|}{$i-\quad$ (n.) } & $+\varnothing$ & $+\mathrm{u}$ & \\
\hline$L$ & /sper $+\mathrm{i} /$ & spere & sper_ $\mathrm{u}^{9}$ & 'spear' \\
\hline$H$ & /gecynd+i/ & gecynd Ø & gecynd Ø $\mathbf{u}$ & 'nature' \\
\hline \multicolumn{2}{|l|}{$i-\quad(\mathrm{f})}$. & $+\varnothing$ & $+\mathrm{a} / \mathrm{e}$ & \\
\hline$H$ & /wyrd-i/ & wyrd Ø & wyrd Ø e, -a & 'fate' \\
\hline \multicolumn{2}{|c|}{$u-\quad$ (m., f. $)$} & $+\varnothing$ & $+\mathrm{a}$ & \\
\hline$L$ & $/ \operatorname{sun}+\mathrm{u} /$ & sunu & $\operatorname{sun}_{-} a$ & 'son' \\
\hline$H$ & $/$ feld $+\mathrm{u} /$ & feld $\varnothing$ & feld $\varnothing$ a & 'field' \\
\hline
\end{tabular}

HVD creates an alternation in the neuter $a$ - class whereby a final $-u$ appears in the nominative plural after a light root but not after a heavy. The rest of the inflections would have been identical in the light and heavy roots. Moreover, because the $a$ - class was the major nominal class, such words were not inclined to be reanalysed as belonging to any other class. Thus, we expect that learners would recognise that nouns with and without an $-u$ suffix in the relevant cases belong to the same declension. From this, it would be fairly easy to recover underlying $-u$ following heavy stems, and with it, the rule of HVD. A similar situation arose in the $\bar{o}$-class 
nouns, but here the $u$ of the stem extension surfaces in the nominative singular after light roots, but not after heavy ones. As this was also a major class, no reanalysis took place.

Matters were somewhat different in the smaller $i$ - and $u$-classes. To start with the latter, the appearance of $-u$ in the nominative of masculine $u$-nouns served to distinguish these nouns from the major $a$-class. Once this suffix was deleted after heavy stems, however, the latter were liable to look, in the nominative singular, like $a$-nouns; thus, feld looks like stān. Despite the distinctiveness of the oblique and plural case endings, heavy $u$-nouns were prone to be reanalysed as $a$-nouns if they were masculine. Even without HVD, the feminine $i$-stems looked, in the nominative singular (and in some dialects also the nominative plural), like $\bar{o}$-stems, and were prone to be reanalysed as such.

Similar challenges faced the other heavy $i$-nouns. Once the distinctive $-i$ suffix had deleted, only the presence of umlauted vowels could, in some cases, signal that a heavy noun was not simply a member of the $a$ - or $\bar{o}$-stems. If umlauted vowels at some point became phonemic (as argued by Dresher (1985) for the Mercian dialect), then there would be no reason to keep these nouns distinct from the major classes.

The $j a$ - and $j \bar{o}$-stems exhibit more complex interactions with HVD. We repeat the singular-plural forms of the neuter $j a$-nouns along with the Gothic forms for comparison. Note that Gothic shows no gemination and umlaut.

(14) Singular-plural alternations in neuter $j a$-class nouns

\begin{tabular}{|c|c|c|c|}
\hline Gothic & Stem & Nom SG $\varnothing$ & NOM PL $u$ \\
\hline *stucc-i & stycc $^{1}{ }^{i}$ & stycc-e & stycc-u \\
\hline * gawad-i & gewǣd+ ${ }^{\mathrm{i}}$ & gewǣd-e & gewǣd-u \\
\hline$*_{\mathrm{a}} \mathrm{\theta al}-\mathrm{i}$ & $æ \theta \mathrm{el}+{ }^{\mathrm{i}}$ & æӨel-e & 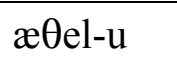 \\
\hline bad-i & bed $+^{i}$ & bedd & bedd- $\varnothing$ \\
\hline kun-i & $\operatorname{cyn}+^{i}$ & cynn & cynn-Ø \\
\hline
\end{tabular}

Formerly light roots that had undergone WGG, such as bedd 'bed' and cynn 'race', became indistinguishable from neuter $a$-nouns. The difference between words like bedd and stycce is that the latter was a real heavy root, whereas the former became 
heavy after gemination. Neuter ja-nouns, such as stycce-styccu 'stick', which were originally heavy, create apparent exceptions to the rule of HVD. There are, in fact, two types of apparent exceptions. In the plural, we find $-u$ immediately following a heavy syllable. In the nominative singular, these nouns surface with a final $-e$, which originates from $-i$.

It has been proposed that these $j a$-nouns joined with the light $i$-nouns to create a new class of nouns with a nominative singular suffix $-e$ (Keyser \& O'Neil 1985). A major problem with this analysis is that it does not account for the plurals with $-u$ after a heavy syllable. Though HVD did have various exceptions here and there, particularly after bisyllabic roots (see Dresher 1985), the application of HVD after heavy roots was virtually without exceptions. Moreover, nouns such as styccu and geweed $d u$ showed the suffix - $u$ with great regularity, and no tendency to 'regularise' it. Therefore, the persistence of surface $-u$ in these cases points to regular, not exceptional, behaviour. Rather, the survival of the $-u$ in these cases can be explained if we assume that these stems maintained their $j$ extension. Therefore, in the plural, it was this element and not the $-u$ which was deleted by HVD. This is the condition in which HVD is blocked before a glide and is shown in (15).

(15) Gemination, HVD, and restructuring of feet in OE neuter nouns

Gemination

a. $a$-stems $H$

$$
\begin{array}{ll}
S G . & \text { word }-\varnothing \\
& ([\mu \mu])
\end{array}
$$$$
P L
$$

$$
\begin{array}{ll} 
& \text { word }-\underline{\mathrm{u}} \\
& ([\mu \mu] \mu)
\end{array}
$$

b. ja-stems $H$

$$
\begin{array}{ll}
S G . & \text { stycc }-\underline{\mathrm{i}}^{\mathrm{i}}-\varnothing- \\
& ([\mu \mu] \mu) \\
P L . & \text { stycc }-\underline{\mathrm{i}}^{\mathrm{i}}-\mathrm{u}- \\
& ([\mu \mu] \mu) \mu
\end{array}
$$

HVD

$\begin{array}{lll}- & \rightarrow & \text { word } \\ & & ([\mu \mu]) \\ \text { word }-\varnothing & \rightarrow & \text { word } \\ ([\mu \mu]) & & ([\mu \mu])\end{array}$




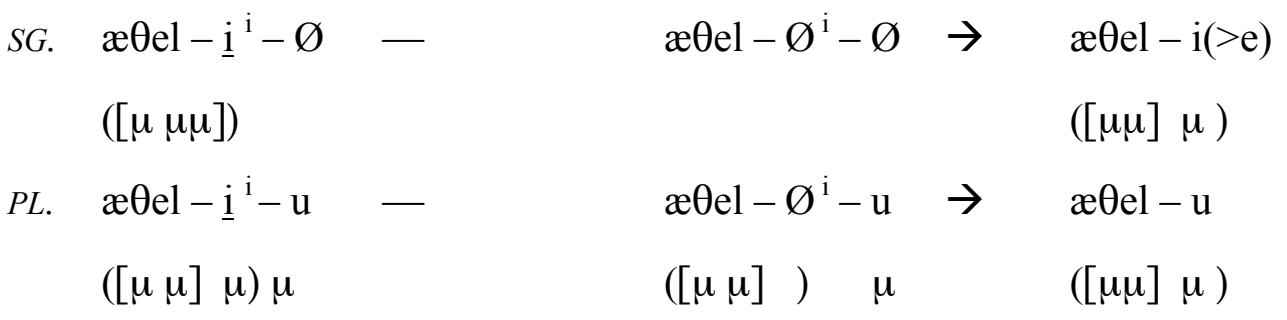

c. ja-stems $L$

\begin{tabular}{|c|c|c|c|c|c|}
\hline$S G$ & $\begin{array}{l}\text { bed }-{ }^{\mathrm{i}}-\varnothing \\
([\mu \mu])\end{array}$ & $\begin{array}{l}\text { bed }-d \\
([\mu \mu])\end{array}$ & bedd & $\rightarrow$ & $\begin{array}{l}\text { bedd } \\
([\mu \mu])\end{array}$ \\
\hline$P L$. & bed $-{ }^{\mathrm{i}}-\underline{\mathrm{u}}$ & bed $-d-\underline{u}$ & bedd - Ø & $\rightarrow$ & bedd \\
\hline & $\mu]$ ) & $([\mu \mu] \quad \mu)$ & $([\mu \mu])$ & & $([\mu \mu])$ \\
\hline
\end{tabular}

The second apparent exception to HVD occurs in the singular, where the $j$ extension surfaces as $-e$. Unstressed $i$ in Old English systematically lowers to $e$; thus, the occurrence of $-e$ is compatible with deriving it from $j$. But why does this element not delete after a heavy syllable, as it does in the plural, deriving *stycc, * gewōed, and

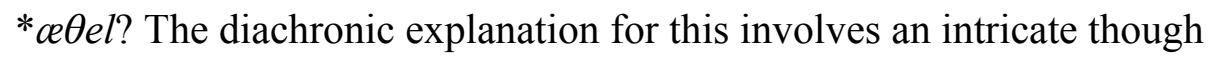
straightforward interaction between Sievers' Law, which provided these forms with an extra high vowel, and High Vowel Deletion. Assuming that the $j$ extension could be recovered in these nouns (an assumption based on the wide-spread evidence for HVD and $i$-lowering, as well as the persistence of $-u$ following heavy stems in these nouns), what a learner could glean is that it deletes like a regular high vowel when medial, but escapes HVD when final. Thus, because of Sievers' Law, HVD had different results on originally light $j a$-stems which became heavy by WGG and $j a$ stems that were originally heavy. Therefore, at a certain period it must have looked to learners of Old English that WGG invariably involved the loss of the triggering $j$. Thus, the loss of the $j$ was folded into the rule of WGG in Old English (Lahiri 1982).

\section{$4 \quad$ From Old English to Middle English}

\subsection{Nominal paradigms in Old English}


After all these changes the resulting paradigms in (16) differ in a number of aspects from the original West Germanic paradigms given in (6). In (16) the forms are arranged by gender.

(16) Survey of strong nominal classes - light and heavy roots

\begin{tabular}{|c|c|c|c|c|}
\hline Class & Weight & SING. & PLUR. & Gloss \\
\hline \multirow{2}{*}{$a-\quad(\mathrm{m})}$. & light & dæg & dag-as & 'day' \\
\hline & heavy & stān & stān-as & 'stone' \\
\hline \multirow{2}{*}{$j a-(\mathrm{m})}$. & light & hyll & hyll-as & 'hill' \\
\hline & heavy & end-e & end-as & 'end' \\
\hline \multirow{2}{*}{$i-\quad(\mathrm{m})}$. & light & byr-e & byr-as & 'son' \\
\hline & heavy & gylt & gylt-as & 'guilt' \\
\hline \multirow{2}{*}{$a-\quad(\mathrm{n})}$. & light & hol & hol-u & 'hole' \\
\hline & heavy & word & word & 'word' \\
\hline \multirow{2}{*}{$j a-(\mathrm{n})}$. & light & bedd & bedd & 'bed' \\
\hline & heavy & gewǣd-e & gewǣd-u & 'clothing' \\
\hline \multirow{2}{*}{$i-\quad(\mathrm{n})}$. & light & sper-e & sper-u & 'spear' \\
\hline & heavy & gecynd & gecynd-u & 'nature' \\
\hline \multirow{2}{*}{$\bar{o}-\quad$ (f.) } & light & tal-u & tal-e, -a & 'tale' \\
\hline & heavy & $\bar{a} r$ & ār-e, -a & 'honour' \\
\hline \multirow{2}{*}{$j \bar{o}-(\mathrm{f})}$. & light & synn & synn-e, -a & 'offence' \\
\hline & heavy & sprēc & sprēe-e, -a & 'speech' \\
\hline \multirow{2}{*}{$i-\quad$ (f.) } & light & ----- & ----- & \\
\hline & heavy & wyrd & wyrd-e, -a & 'fate' \\
\hline \multirow{2}{*}{$u-\quad(\mathrm{m} ., \mathrm{f})}$. & light & sun-u & sun-a & 'son' \\
\hline & heavy & feld & feld-a & 'field' \\
\hline
\end{tabular}

Compared to the original symmetrical system of long and short stems there are a number of important changes. First, masculine endings are $\varnothing$ or $-e$ (from $i$ ) in the singular, and $-a s$ in the plural. Neuter singulars either end in $\varnothing$ or $-e$ (from $i$ ); plurals in $\varnothing$ or $-u$. Feminine singular forms end in either $-u$ or $\varnothing$; plural endings always $-e$, $-a$. Thus, any variation in the singular invariably involves the presence or absence of 
a high vowel, which originates from the stem extension, as all classes have a $\varnothing$ ending in the nominative singular. In the plural each gender has its own ending: -as, -e/a and - $\underline{\mathrm{u}}$ for masculine, feminine and neuter, respectively.

In the forms with an underlying $j$, the $-e$ or $-u$ ending is maintained after originally heavy stems, but not after originally light stems made heavy by WGG. In both cases, the stem invariably has a front vowel due to Umlaut. In other words, the original heavy-light distinction is preserved, as well as the Umlaut factor. In the other cases with variable endings, the ending $-e$ or $-u$ shows up after light stems, but not usually after heavy stems. If the $-u$ is preserved after heavy stems the stem vowel is umlauted. Again, the original heavy-light distinction is maintained, as well as the source for Umlaut. Thus, there definitely is a relationship between the quality of the root vowel and the overt suffixes, which must have been obvious to the language learner. The morphological classes were clearly still - to a large extent - transparent to the learners of Old English. The singular has no overt suffix, while the plural suffix depends on gender and class; $-a s$ for the masculines, $-u$ for the neuters, and $-e,-a$ for the feminines. In addition, we assume the stem extensions $-j$ and $-i$, which underlyingly contrast as shown in (11b).

Of interest is that despite all the changes the underlying contrasts are still recoverable to the Old English learner. Indeed the learner appears to be quite conservative. However, a number of other prosodic rules took place, which affected the recoverability to a great extent, which we will discuss next.

\subsection{Prosodic preferences and the pertinacity of the Germanic foot}

The Old English metrical structure, inherited from its Germanic ancestor, served as a template that influenced a number of further prosodic developments. In these developments we will observe the pertinacity of a basic metrical structure, even if its application to particular forms results in new output forms, due to novel interactions with new phonological processes.

The Old English metrical structure, discussed in section 2, is relevant for the phenomenon of Trisyllabic shortening (TSS): in a three-syllable word, the vowel of the first stressed syllable is shortened. TSS was already present in Old English (Hogg 1992: §5.199-5.201). In the early stages, TSS applied when the long vowel was followed by two consonants or a geminate, that is, in closed syllables; later the process also affected long vowels before single consonants, that is, in open syllables 
(Luick 1914/1964: $§ 204, \S 353$ ). This shortening occurred primarily in inflected forms, although there are some early examples with derivational suffixes as well, as in

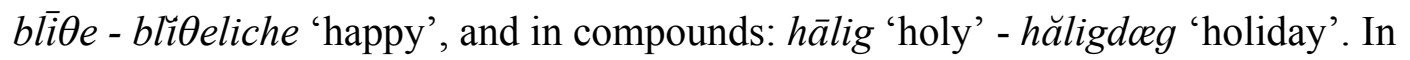
disyllabic nouns TSS created a short vowel in trisyllabic plural forms where the nominative singular had a long vowel. The following examples illustrate the alternations:

(17) TSS in late Old English

$\begin{array}{lll}\begin{array}{l}\text { Singular } \\ \text { cicen }\end{array} & \begin{array}{l}\text { Plural } \\ \text { cĭcenu }\end{array} & \text { 'chicken' } \\ \text { hēafod } & \text { hĕafodu } & \text { 'head' } \\ \text { ǣnig } & \text { æ̌nige } & \text { 'any' } \\ \text { clōver } & \text { clăvere } & \text { 'clover' } \\ \text { hǣring } & \text { hæuringas } & \text { 'herring' }\end{array}$

TSS changed the prosodic shape of a word of the form $([\mathrm{H}] \mathrm{L}) \mathrm{L}$ to $([\mathrm{L} \mathrm{L}] \mathrm{L})$. Whereas the older form comprised a foot plus a syllable, the newer form makes up a maximal foot.

Another rule that redistributed the syllables of a word within a foot was Open Syllable Lengthening (OSL), which became established in early Middle English. OSL caused a stressed vowel to lengthen in an open syllable, and affected native words like beofor > bēofor 'beaver' as well as Latin loans such as vāne ([va:nə], not *văne). This rule primarily affected bisyllabic words; in trisyllabic words, TSS ensured that the stressed vowel would remain short. The effect of OSL was to convert a word of the form [L L] to [H L]; like TSS, this rule also resulted in a maximal foot.

We hypothesise that these changes are in keeping with a set of prosodic preferences, defaults that learners adhere to, or tendencies that exert a pressure in a certain direction. Lahiri \& Dresher (1999) posit the following preferences:

(18) Prosodic preference scales and principles of interpretation

a. Maximisation of foot: (Hd Dep) » $(\mathrm{Hd})$

b. Incorporate unfooted syllables into feet 
c. Maximisation of head:

$([\mathrm{H}]) »([\mathrm{LH}]) »([\mathrm{~L}])$

d. Main stressed foot not less complex than secondary stressed feet

The notable preferences are to maximise the foot size (18a) and minimise the number of unfooted syllables (18b). However, as a result quantity alternations appeared in the nominal paradigms. Romance loans in Middle English were subject to the same preferences and hence show quantity alternations in morphologically related words, as shown in (19) (see Lahiri \& Fikkert 1999).

(19) Prosodic preferences giving rise to quantity alternations
a. $([\mathrm{H}] \mathrm{L})$ » $([\mathrm{LL}])$
(OSL) vāne rather than văne
b. $([\mathrm{L} \mathrm{L}] \mathrm{L}) »([\mathrm{H}] \mathrm{L}) \mathrm{L} \quad(\mathrm{TSS})$ vănity rather than vānity

\subsection{Levelling in Middle English: The collapse of the quantity distinctions in nouns} In the preceding sections we observed a series of prosodic changes that, while resulting in changes in surface forms, exhibited a certain conservatism, or pertinacity, in the grammar. But radical upheavals in the grammar also occur. In this section we will observe how the interaction of OSL and TSS caused the long-enduring underlying quantity distinction between light and heavy roots in nouns to finally become obscure to the point where they could no longer be maintained by language learners.

In early Old English there were no rules that created alternations of the quantity of root syllables in nominal paradigms. WGG had changed light syllables into heavy ones, but this rule tended to affect entire nominal paradigms. Once OSL and TSS became established, however, quantity alternations within nominal paradigms were created. The nature of the alternation depended on the number of syllables in the root and inflectional suffixes. The expected quantity alternations of some representative noun classes are given in the table in (19); 'expected' because, as the reader will immediately notice, the PDE reflexes of these nouns do not display any quantity alternations. The reason for this is the subject of this section. 'L' stands for long vowels, 'S' for short ones. 
(20) Predicted effects of OSL and TSS on Old English noun classes in Middle English

\begin{tabular}{|c|c|c|c|c|c|c|}
\hline & & Old English & & $\begin{array}{l}\text { Expected ME } \\
\text { vowel length }\end{array}$ & & $\begin{array}{l}\text { PDE } \\
\text { vowel }\end{array}$ \\
\hline & Endings & Singular & Plural & after OSL/TSS & Gloss & length \\
\hline a. & $V-V$ & talu & tala & $\mathrm{L}-\mathrm{L}$ & 'tale' & $\mathrm{L}$ \\
\hline b. & $\varnothing-\mathrm{V}$ & hwæl & hwalas & $S-L$ & 'whale' & $\mathrm{L}$ \\
\hline c. & $\varnothing-V$ & beofor & beoferas & $\mathrm{L}-\mathrm{S}$ & 'beaver' & $\mathrm{L}$ \\
\hline d. & $\varnothing-V$ & dēofol & dēofelas & $\mathrm{L}-\mathrm{S}$ & 'devil' & $\mathrm{S}$ \\
\hline e. & $\varnothing-V$ & hyll & hyllas & $S-S$ & 'hill' & $\mathrm{S}$ \\
\hline
\end{tabular}

The most straightforward classes are (20a), which are the OE $n$-class nouns and light $i-, u-, \bar{o}$-nouns, and (20e), which typically are the OE light $j a$-and $j \bar{o}$-class nouns, in which the coda consonant was geminated after a short vowel (WGG). We expect OSL in both the singular and the plural for (20a), and no OSL in (20e). Thus, no alternations are expected in ME. Because the root vowels in (20a) were long throughout the paradigm, with no indication that they remained underlying short, learners would have learned them as long vowels. If we look at some of the Old English words with short root vowels in disyllables throughout the paradigm, they are almost all long vowels in Present Day English: OE apa 'ape', blcese 'blaze', bracu 'brake', cwene 'queen', fola 'foal', nama 'name', nosu 'nose', slege 'slay', smoca 'smoke', snaca 'snake', stole 'stole', etc. In contrast, words with geminates following short vowels are nowadays all short, as in Old English bridd 'bird', cnyll 'knoll', dynn 'din', hrycg 'ridge', etc.

The monosyllabic stems in (20b) descend from the $a$-nouns, which have a closed syllable in the singular and an open syllable in the plural. We expect OSL to apply only in the plural. Thus, the singulars should have emerged with short vowels and the plurals with long vowels. But such alternations do not exist in Modern English.

If we look systematically at this noun class, we find that these nouns have levelled in both directions. Lahiri \& Dresher (1999) and Dresher (2000) report that in their collection of $a$-nouns 19 nouns have a short vowel in Modern English and 17 have a long vowel (cf. (21)), a proportion of $53 \%$ short to $47 \%$ long. 
(21) Examples of OE monosyllabic $a$-stems with short vowels

a. Short in NE: back, bath, black, brass, broth, chaff, glass, god, grass, lock, lot, path, sap, shot, staff, swath, thatch, vat, wer[wolf]

b. Long in NE: bead, blade, coal, crate, dale, day, door, fare, gate, grave, hole, hope 'recess', meet, sole 'mud', way, whale, yoke

The data in (20c) represent Old English disyllabic stems with short stressed vowels in open syllables. Such nouns are disyllabic in uninflected forms, and trisyllabic when an inflectional suffix is added. According to Lahiri \& Dresher, the first vowel in the disyllabic forms would have been lengthened by OSL, but the trisyllabic forms would have been subject to the overriding effects of TSS: expected ME be efor/beofaras. The pattern in (20d) represents Old English disyllabic nouns with an original long vowel. Such nouns would have been subject to TSS in the plural (expected ME dêfal/deofalos) and should thus have become identical in vowel quantity to the disyllables with original short vowels in (20c).

Assuming that the hypothesised length alternations were subsequently levelled, the levelling should again go in both directions. The descendants of these nouns are indeed found as both long and short in Modern English, as shown in (22).

(22) OE disyllabic nouns (20c, d) With short vowels in open syllables

a. Long in PDE: bydel 'beadle', beofor 'beaver', cradol 'cradle', efen 'even', nacod 'naked',

b. Short in PDE: camel 'camel', canon 'canon', copor 'copper', fæder 'father'

With long vowels in open syllables

a. Long in PDE: bēacen 'beacon', bìtel 'beetle', stȳpel 'steeple', tācn 'token', fēfor 'fever'

b. Short in PDE: brōӨor 'brother', fōdor 'fodder', hǣring 'herring', wǣpen 'weapon' 
In sum, in the forms in $(20 \mathrm{a}, \mathrm{e})$ quantity variation is neither expected nor attested in PDE. The cases in (20b-d) where we expected variation indeed show variation in PDE. These results are entirely consistent with our hypothesis of OSL and TSS followed by levelling. Reflexes of original short vowels are short in $58 \%$ of the words and long in $42 \%$. Original long vowels come out $53 \%$ short and $47 \%$ long. We therefore conclude that paradigmatic levelling of quantity plays an important role in the outcome of vowel length in English.

What can we say about the bidirectionality of the levelling? We know that at some point after OSL and TSS, the inflectional vowel was deleted. Then we would expect alternations such as: $n \bar{a} m \sim n \bar{a} m s$, god gōds, and bēver bevers. For $n \bar{a} m \sim n \bar{a} m s$, the vowel length is entirely consistent; but with the loss of the inflectional vowel in god gōds and bever bevers, the motivation for the length alternation disappears.

Assuming no further adjustment of vowel length, the loss of the inflected vowel leaves the vowel length situation in a confused state. In some words, there is lengthening in the plural, but no change in syllable structure, while in other words the plural is associated with shortening. Some nouns have long vowels in both singular and plural, like name, and others, are always short, like bed $(d)$. But in the majority of cases, the alternation has become phonologically incoherent. Even a morphological rule appears to be unavailable: we cannot, for example, associate length with any particular morphological category. In such circumstances, paradigm uniformity may step in. On this account, language learners choose a consistent vowel quantity. This may proceed on a word-by-word basis, in which case we might expect a fairly even split in outcomes.

In other words, once underlying contrasts are no longer recoverable, the situation is open to reanalysis by the learner. This happened in Middle English. Interestingly, although quantity alternations also appeared in derivationally related words, such as in vain - vanity, these have not been levelled out. However, these loans were not borrowed as derivationally related (Lahiri \& Fikkert 1999). The 'suffixed' trisyllabic words like vanity (1230) and sanity (1432) were borrowed as independent words and in fact, often borrowed earlier then the adjective vane (1300) and sane (1628). The fact that these words were borrowed according to the prosodic system of Middle English provides evidence that direction of parsing and placement of main stress had not changed in Middle English. 


\section{Changes in stress: Middle English to early Modern English}

Although the changes sketched above had a dramatic effect on nominal paradigms, they had no effect on the position of main stress, and the stress system in Middle English remained essentially as in Old English. However, the various changes did have the effect of metrically 'shortening' many words. Thus, words which in Old English had more than one foot were often reduced to a single foot in Middle English, as shown in (23).

(23) Metrical shortening from Old to Middle English

\begin{tabular}{|c|c|c|c|c|}
\hline a. & *hếringes & b. *lắverke & c. *cícenes & d. *clávere \\
\hline $\mathrm{OE}$ & $(\mathrm{H})(\mathrm{H})(\mathrm{H})$ & $(\mathrm{H})(\mathrm{HL})$ & $(\mathrm{H} \mathrm{L})(\mathrm{H})$ & $(\mathrm{H} \mathrm{L}) \mathrm{L}$ \\
\hline CEM & (H) (HL) & - & $(\mathrm{H} \mathrm{L}) \mathrm{L}$ & - \\
\hline TSS & $([\mathrm{L} \mathrm{H}] \mathrm{L})$ & $([\mathrm{L} \mathrm{H}] \mathrm{L})$ & $([\mathrm{L} \mathrm{L}] \mathrm{L})$ & ([LL]L) \\
\hline $\mathrm{ME}$ & hěringes & lǎverke & cícenes & clăvere \\
\hline
\end{tabular}

Old English words already tended to be short. Moreover, many Old English suffixes were, as they still are today, 'stress neutral', meaning they do not participate in the stress domain. Adding the further metrical shortenings described above, native English words tended to be no longer than a single foot. Therefore, evidence for setting the parameters of directionality and main stress was in relatively short supply. Both Old English and Middle English had stress on the root-initial syllable, regardless of quantity. Feet were built iteratively from left to right, resulting in secondary stressed feet in longer words, which, however, were becoming increasingly rare. Recall that final syllables did not have secondary stress, a fact we accounted for in the earlier period by defooting (3), and in the later period by consonant extrametricality (CEM) (4).

In Modern English stress is Latinate (Hayes, 1995): stress falls on the penultimate syllable if heavy, otherwise on the antepenultimate syllable. Final syllables are extrametrical and stress is assigned from right to left. The old and new systems are sketched in (24). 
OE/ME to PDE stress shift

a. Stress in Old and Middle English: Left to right, main stress left
i) $(\underline{\underline{L}} \mathrm{~L})(\underline{\mathrm{H}} \mathrm{L})$
ii) $(\underline{\underline{L}} \mathrm{H}$ L)
iii) $(\underline{\underline{L}} \mathrm{~L} L)$

b. Stress in Modern English: Right to left, main stress right (and final syllable extrametricality)
i) $(\mathrm{L} \mathrm{L})(\underline{\underline{\mathrm{H}}})<\mathrm{L}>$
ii) $\mathrm{L}(\underline{\underline{\mathrm{H}}})<\mathrm{L}>$
iii) $(\underline{\underline{\mathrm{L}}} \mathrm{L})<\mathrm{L}>$

Despite the changes in the stress system, all native Old English words retained their output stress contours in Modern English, such as wáter, hópefulness, begín, even though the metrical structures that underlie them have changed. Contrary to Halle \& Keyser (1971), who place the origins of the change in the time of Chaucer, Lahiri \& Fikkert (1999), Fikkert (2003) and Dresher \& Lahiri (2004) date the important innovations to a later time, due to the influence of Latin borrowings.

Among the Latin words that began entering the language in great numbers in the 16 th century were many that were relatively long, that is, contained more than one foot. These Latin loan words were thus able to fill the gap left by the native words. Without contradicting the majority of the native words, the loan words eventually caused the resetting of the directionality and main stress parameters. Thus, borrowings can be decisive when the core native vocabulary cannot decide between grammars. We argued that Romance loans into Middle English were borrowed with the native prosodic preferences at the time of borrowing and did not come in with their foreign stress pattern. However, where the evidence for directionality and main stress is no longer clear from the native vocabulary, the learner may use the stress pattern of loan words to determine directionality and stress.

However, there is no evidence that either the Old French or the Latin stress rule gained a foothold in English at the time of Chaucer (see also Minkova 1997, Redford 2003). In other words, language users do not adopt a prosodic system of another language. But, large-scale borrowing did affect the language system as a whole, because the make-up of the vocabulary changed considerably. The native vocabulary, which mainly consisted of words of the prosodic shape of one foot (see also Minkova, this volume), was extended with longer Latin words. These longer Latin words did not all enter the language at the same time nor with the same prosodic 
structure, as can be seen in (25). Early borrowings had the Old and Middle English leftward directionality, as shown in (25ab), whereas in later borrowings directionality seems to have shifted rightwards $(25 \mathrm{~cd})$. The dates refer to the first occurrence according to the OED.

(25) Change in directionality

Early borrowings: Foot direction Leftward, Main stress Left
a. $\quad\left(\begin{array}{lll}x & .\end{array}\right)\left(\begin{array}{ll}x & .\end{array}\right)$
b. $\quad\left(\begin{array}{ll}\mathrm{x} & .\end{array}\right)$
$\mu \mu \quad \mu \quad \mu \quad \mu$
$\mu \mu \mu$
com pa ra ble (1413)
re si dence (1386)

Later borrowings: Foot direction Rightward, Main stress Left

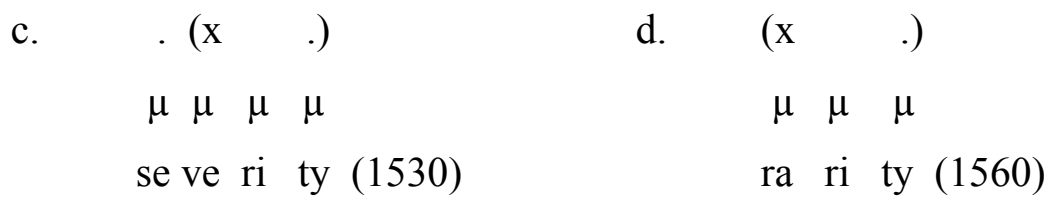

Borrowing Latin words alone could not provoke the native speakers to change directionality. This change in direction came with the introduction of words with Latin suffixes such as -ation, -ic(al), -ity, -ator, -able/-ible, etc. In such forms, stress is computed from the right side. Compare the analyses of comparable and résidence, borrowed when direction of parsing was still from the left, with those of severity and rárity, borrowed after the change in parsing direction. Notice that the change in direction is evident only in (25c) and not in the others (underlined consonants are extrametrical).

These long Latin loan data in early Modern English suggest that (a) the directionality of parsing changed from leftwards to rightwards, and (b) that the main stress parameter did not immediately change together with the directionality parameter. Approximate dates of changes in metrical structure are given in (26), where the foot still is the Germanic resolved moraic trochee throughout:

(26) Sequence of changes in stress parameters

1400: Foot direction Leftward, Main stress Left (as in OE)

1530: Foot direction Rightward, Main stress Left.

1660: Foot direction Rightward, Main stress Right 
Classical words were pronounced by native speakers in the English pronunciation, with alternating secondary stresses two syllables before the tonic (e.g. Latin àcadémia; see Danielsson, 1948, Walker, 1791/1831). When 'Englished', the tonic and countertonic change places to conform to English 'speech habits' (e.g. ácadèmy). Thus, a word like ácadèmy clearly shows two feet, of which the left has the main stress. Therefore, it is not correct to say that English gradually moved from a 'Germanic' to a 'Romance' stress system. In this case, the same words that provoked a change of directionality to right reinforced the evidence for main stress left.

What exactly caused the main stress parameter to finally switch to right is not entirely clear to us. However, a likely place to look is around or before 1660 . According to Danielsson (1948:29), that year was the 'turning point' when French words kept final accent in English, as with suffixes like those in (27) below.

(27) Suffixes retaining main stress: -eer, -ee, -ade, -esque, -ette, -oon. cannoneer (1562), grenadier (1676), payee (1758), parade (1656), arabesque (1611)

Though some words may have entered the language before 1660, they may not have systematically retained final stress until around that date. It is plausible to suppose that final stress in words with these suffixes became more systematic after the change of main stress to right.

\section{Conclusion}

We have discussed the phonological and morphological system from Old English to early Modern English with reference to constraints on prosodic structure, the quantity of root syllables, foot structure, and prosodic preferences. In Old English, both the weight of root syllables and morphological class membership were still important factors in prosodic change. To the language learner these classifications clearly still were transparent to a large extent. In Middle English, morphological class membership became opaque due to the reduction of morphological endings. Moreover, the weight of root syllables became less transparent, due to the interaction 
of various phonological processes, such as TSS and OSL. In the face of such opacity the language learner could not reconstruct the old system and instead opted for paradigmatic levelling of quantity in the nominal paradigms. However, these reanalyses did not affect prosodic preferences, nor did the foot structure change.

Crucial evidence comes from loans, which are adapted by the adult native speaker, conforming to the prosodic system of the native language. The language learner is indeed quite conservative and will only change the system if (s)he is faced with more than one conflicting prosodic option. After metrical weakening reduced most native words to one foot, the prosodic system had no way of deciding on directionality for words that were longer. In this case, the non-native vocabulary played a decisive role for the language learner. Importantly, the loans were not adopted with the prosodic system of the donor language. Language learners are conservative and do not change the prosodic preferences nor do they change underlying representations as long as they are still recoverable. Only if underlying representations are no longer recoverable - because of the interaction of phonological rules - will the learner resort to innovative strategies such as paradigm levelling, which can have dramatic consequences for both underlying representations and the grammar.

\footnotetext{
Notes

* Paula Fikkert would like to thank both KNAW and NWO for respectively funding the research projects 'The development of prosodic systems of West Germanic: Learnability and change' and 'Changing Lexical Representations in the Mental Lexicon'. Elan Dresher's research was supported in part by grant 410-2003-0913 from the Social Sciences and Humanities Research Council of Canada. The research of Aditi Lahiri was partly supported by funds from the Deutsche Forschungsgemeinschaft (Sonderforschungsbereich 471 and the Leibniz Prize).

${ }^{1}$ We will not be concerned here with intonation and other aspects of speech rhythm, which are also commonly considered to be part of prosody.

${ }^{2}$ The philological literature refers to noun stems and verb roots. A 'stem-extension' was added to all Proto-Germanic nominal roots. Here, by stems we mean nominal roots plus their extensions. That is, the stem is the element to which gender/number/case suffixes are added.

${ }^{3}$ Modern English still does not allow monosyllabic words with a non-branching rhyme (V), even though light syllables can occur in the language.

${ }^{4}$ There are other morphological classes in Old English which we have not discussed for reasons of space. There is a $w a$-class as well as the weak declension, $n$-class, and the consonantal stems. These classes also follow the weight sensitive processes.

${ }^{5}$ The prefix ge-in geweed and gecynd is unstressed. Stress falls on the root in nouns.
} 